Journal of Social Sciences 7 (3): 309-314, 2011

ISSN 1549-3652

(C) 2011 Science Publications

\title{
The Relation between Physiological Parameters and the Anxiety State in Competitive Men Handball Players During Official Competitions
}

\author{
${ }^{1}$ Alexandru Acsinte, ${ }^{1}$ Eftene Alexandru, ${ }^{2}$ Alexandru Păcuraru, \\ ${ }^{3}$ Petru Ghervan and ${ }^{4}$ Ion Mihăilă \\ ${ }^{1}$ University" Vasile Alecsandri" of Bacau, \\ Faculty of Movement, Sports and Health Sciences, \\ 2" Dunarea de Jos" University of Galați, \\ 3"Stefan cel Mare" University of Suceava, \\ ${ }^{4}$ University of Piteşti, Physical Education and Sport Faculty, Romania
}

\begin{abstract}
Problem statement: The aim of this study was to examine the blood biochemical and physiological changes that occur during competitions in elite handball players-men in a specific kind of anxiety state. The grounding, elaboration, verification and evaluation of a scientific concept based on psychological, physiological and biochemical guidance of the effort in competitive handball in order to generalize it at national level, imply the following: Establishing if and in which measure, the stress factors that act upon handball players during the official competition influence the modification dynamics of certain physiological factors being in direct correlation with effort capacity and focusing on the capacity of influencing, controlling and directing the stress factors in the sense of obtaining certain physiological parameters values necessary for a great performance. The research has emphasized the fact that this method of studying the factors that intervene in obtaining performances in handball is not yet applied on a national level, this aspect not being a priority for the specialty federation representatives, although this kind of collaboration with specialists from other fundamental areas, associated with competitive sports, has given world-wide remarkable results in other sports. Approach: The selected subjects for the experiment were male handball players in the Internal Championship-Romanian National League-male. Our experiment focused on each team's ten most valuable players (The first seven title players and the first three most valuable reserves), resulting 50 subjects from the male teams. The selection criterion was number of times they played as title players in the Romanian Championship games, their participation in centralized training sessions with the Romanian representative teams, as well as their play in the Romanian National Team. Blood samples were drawn 3 min after finishing the match in order to determine $\mathrm{pH}$, oxygen partial Pressure $\left(\mathrm{P}_{\mathrm{O} 2}\right)$, carbon dioxide partial pressure $\left(\mathrm{PCO}_{2}\right)$, concentration of Hydrogen Carbonate $\left(\mathrm{HCO}_{3}{ }^{-}\right)$, Base Excess (BE), Standard Base Excess (SBE), Standard Bicarbonate (SBC), Lactic Acid (LA) and relation $\mathrm{SBC} / \mathrm{HCO}_{3}{ }^{-}(\mathrm{R})$. Conclusion/Recommendations: After match all parameters studied changed their value significantly $(\mathrm{p}<0.001)$ in all teams. These results demonstrate that handball demanding in a highly aerobic with a considerable anaerobic component (as in official competition) requiring high lactate tolerance. Training programmed should reflect these demands placed on players during competitive matchplay. The purpose of this study was accomplished, confirming some of theories in the sportive from a psychological point of view of approaching the sportive competitions. Data can represent a starting point in thorough study of the handball coaching principles.
\end{abstract}

Key words: Physiological parameters, coaching principles, base excess, carbon dioxide, partial pressure

\section{INTRODUCTION}

The grounding, elaboration, verification and evaluation of a scientific concept based on the psychological, physiological and biochemical guidance of the effort in competitive handball in order to generalize it at national level, imply the following:
- Establishing if and in which measure, the stress factors that act upon the handball players during the official competition influence the modification dynamics of certain physiological factors being in direct correlation with the effort capacity

- The capacity of influencing, controlling and directing the stress factors in the sense of obtaining 
certain physiological parameters values necessary for a great performance

The research has emphasized the fact that this method of studying the factors that intervene in obtaining performances in handball is not yet applied on a national level, this aspect not being a priority for the specialty federation representatives, although this kind of collaboration with specialists from other fundamental areas, associated with competitive sports, has given world-wide remarkable results in other sports (Acsinte and Alexandru, 2004; Adamu et al., 2010; Alexandru and Eftene, 2007; Avraham et al., 2003; Baker et al., 2002; Hnidawei et al., 2010; Kordi et al., 2009).

Hypothesis: If the value dynamics of certain physiological indicators is influenced by the handball players' anxiety state, then their play during an official match can be significantly affected.

Subjects and protocol: The selected subjects for the experiment are male handball players in the Internal Championship-Romanian National League - male. Our experiment is focused on each team's ten most valuable players (The first seven title players and the first three most valuable reserves), resulting 50 subjects from the male teams. The selection criterion was the number of times they played as title players in the Romanian Championship games, their participation in the centralized training sessions with the Romanian representative teams, as well as their play in the Romanian National Team.

The testing, before and after the match, was made during an Indoor Handball Tournament. The blood samples were taken at approximately $3 \mathrm{~min}$ after the official games were over, with the verbal consent of each tested player. The blood was taken from the middle finger into $200 \mu \mathrm{L}$ glass heparin zed capillary tubes. The capillary tubes were closed at both ends with devices made from a special material, in order not to allow any modification of the blood gas pressure.

We also mention that $30 \mathrm{~min}$ before the official matches, the forms with the Hamilton anxiety evaluation tests were distributed and completed.

\section{MATERIALS AND METHODS}

The ABL5 blood gas analyzer: In order to evaluate the effort metabolic cost, the recovery degree of the body after effort and the working efficiency of different energy sources, reflected in the acid-base balance, we can use the"ABL5 blood gas analyzer" made by Radiometer company of Copenhagen, that allows determining ten connected parameters: Hemoglobin ( $\mathrm{Hb}$ ), $\mathrm{pH}, \mathrm{PcO}_{2}$ (the $\mathrm{CO}_{2}$ blood partial pressure), $\mathrm{Po}_{2}$ (the
$\mathrm{O}_{2}$ blood partial pressure), Actual Plasmatic Bicarbonate $\left(\mathrm{HCO}_{3}{ }^{-}\right)$, Total Carbon Dioxide $\left(\mathrm{TCO}_{2}\right)$, BE (bases excess), SBE (standard bases excess), SAT (hemoglobin oxygen saturation), Standard Bicarbonate (SBC). $\mathrm{R}$ is the value of relation between $\mathrm{SBC}$ and $\mathrm{HCO}_{3}{ }^{-}\left(\mathrm{SBC} \mathrm{HCO}_{3}{ }^{-}\right)$. At rest condition its normal value is 1. Any variation up and down indicate breathing or metabolic disorders determined by effort intensity. These parameters are corrected and correlated by a microcomputer inside the device, depending on the atmospheric pressure measured by an electronic barometer. The atmospheric pressure, $\mathrm{Hb}, \mathrm{pH}, \mathrm{Pco}_{2}$ and $\mathrm{Po}_{2}$ are measured directly, the other parameters being calculated by the computer programs and all are automatically recorded on a paper tape. The relation and dynamic of the physiological markers respect the Sigaard-Andersen nomogram.

The samples can be preserved for three hours at a temperature of $4^{\circ} \mathrm{C}$.

The Hamilton anxiety scale: It is the relatively most used anxiety estimation scale. It was designed to be used on subjects with an anxiety diagnosis, in order to evaluate the severity of the anxiety state $(\mathrm{CH})$. The evaluation scale is the following:

- From 0-5, lack of anxiety state

- From 6-14, minor state of anxiety

- Over 15, major state of anxiety

\section{RESULTS}

The tested physiological parameters dynamics during the official handball competition: The evolution of the parameters in the above mentioned conditions can be observed in the following tables, the data being presented under the form of averages made at each team level, in every experimental variant (Table 1-2).

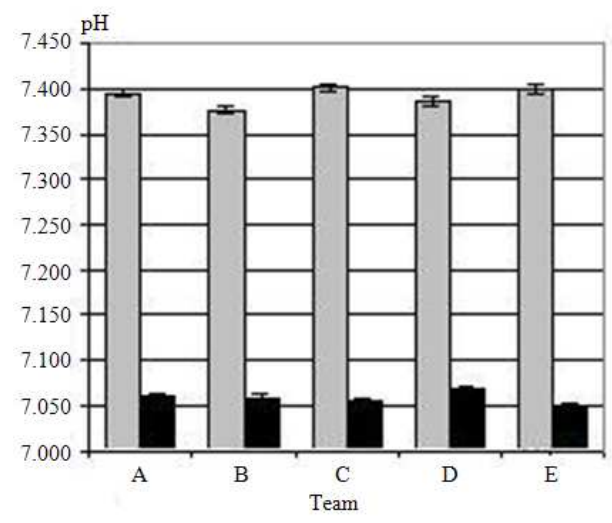

Fig. 1: The $\mathrm{pH}$ values dynamics before and after the official game at male teams 
Table 1: The tested parameters values dynamics before the official game at the male teams (the values represent the arithmetical mean \pm ES)

\begin{tabular}{|c|c|c|c|c|c|c|c|c|c|c|}
\hline \multirow[b]{2}{*}{ Team } & \multirow[b]{2}{*}{$\mathrm{pH}$} & \multirow[b]{2}{*}{$\operatorname{Pco} 2(\mathrm{mmHg})$} & \multirow[b]{2}{*}{$\mathrm{Po} 2(\mathrm{mmHg})$} & \multirow[b]{2}{*}{$\mathrm{HCO} 3(\mathrm{mM} / \mathrm{l})$} & \multicolumn{4}{|c|}{ The tested physiological parameters } & \multirow[b]{2}{*}{$\mathrm{R}$} & \multirow[b]{2}{*}{$\mathrm{CH}$} \\
\hline & & & & & $\mathrm{BE}(\mathrm{mM} / \mathrm{l})$ & $\mathrm{SBE}(\mathrm{mM} / \mathrm{l})$ & $\mathrm{SBC}(\mathrm{mM} / \mathrm{l})$ & $\mathrm{LA}(\mathrm{mM} / \mathrm{l})$ & & \\
\hline $\mathrm{A}(\mathrm{n}=10)$ & $7.396 \pm 0.014$ & $37.100 \pm 2.019$ & $77.800 \pm 7.837$ & $22.000 \pm 0.667$ & $-1.900 \pm 0.433$ & $-2.000 \pm 0.558$ & $22.800 \pm 0.327$ & $.892 \pm 0.343$ & $1.041 \pm 0.025$ & $14.600 \pm 0.991$ \\
\hline$B(n=10)$ & $7.377 \pm 0.007$ & $38.100 \pm 0.983$ & $76.200 \pm 7.038$ & $22.000 \pm 0.447$ & $-2.500 \pm 0.401$ & $-2.400 \pm 0.452$ & $22.300 \pm 0.396$ & 318 & \pm 0.011 & $18.300 \pm 1.155$ \\
\hline$C(n=10)$ & $7.402 \pm 0.014$ & $34.600 \pm 1.784$ & $72.000 \pm 7.233$ & $21.000 \pm 0.577$ & $-2.800 \pm 0.359$ & $-3.100 \pm 0.433$ & $22.100 \pm 0.277$ & $2.604 \pm 0.285$ & $1.056 \pm 0.024$ & $17.900 \pm 1.080$ \\
\hline$D(n=10)$ & $7.386 \pm 0.011$ & $38.000 \pm 1.633$ & $83.100 \pm 7.355$ & $22.100 \pm 0.605$ & $-2.100 \pm 0.433$ & $-2.000 \pm 0.558$ & $22.800 \pm 0.389$ & $2.051 \pm 0.343$ & $1.035 \pm 0.023$ & $13.800 \pm 0.904$ \\
\hline$E(n=10)$ & $7.401 \pm 0.015$ & $35.100 \pm 1.946$ & $74.600 \pm 7.590$ & $22.000 \pm 0.646$ & $-2.700 \pm 0.396$ & $-2.900 \pm 0.526$ & $22.300 \pm 0.367$ & $2.525 \pm 0.314$ & $1.056 \pm 0.025$ & $16.900 \pm 1.464$ \\
\hline Average & $7.392 \pm 0.012$ & $36.580 \pm 1.673$ & $76.740 \pm 7.410$ & $21.820 \pm 0.588$ & $-2.400 \pm 0.405$ & $-2.480 \pm 0.505$ & $22.460 \pm 0.351$ & $2.288 \pm 0.321$ & $1.040 \pm 0.022$ & $16.300 \pm 1.119$ \\
\hline
\end{tabular}

Table 2: The tested parameters values dynamics after the official game at the male teams (the values represent the arithmetical mean \pm ES) The tested physiological parameters

\begin{tabular}{|c|c|c|c|c|c|c|c|c|c|}
\hline Team & $\mathrm{pH}$ & Pco2 $(\mathrm{mmHg})$ & Po2 $(\mathrm{mmHg})$ & $\mathrm{HCO} 3(\mathrm{mM} / \mathrm{l})$ & $\mathrm{BE}(\mathrm{mM} / \mathrm{l})$ & $\mathrm{SBE}(\mathrm{mM} / \mathrm{l})$ & $\mathrm{SBC}(\mathrm{mM} / \mathrm{l})$ & $\mathrm{LA}(\mathrm{mM} / \mathrm{l})$ & $\mathrm{R}$ \\
\hline $\mathrm{A}(\mathrm{n}=10)$ & $7.060 \pm 0.017$ & $51.100 \pm 1.159$ & $49.800 \pm 6.042$ & $13.900 \pm 0.433$ & $-16.800 \pm 0.757$ & $-14.600 \pm 0.618$ & $12.100 \pm 0.433$ & $13.683 \pm 0.599$ & $0.865 \pm 0.013$ \\
\hline B $(n=10)$ & $7.059 \pm 0.011$ & $51.500 \pm 0.342$ & $39.500 \pm 0.885$ & $14.200 \pm 0.416$ & $-16.000 \pm 0.494$ & $-14.800 \pm 0.554$ & $12.800 \pm 0.416$ & $13.050 \pm 0.391$ & $0.882 \pm 0.012$ \\
\hline$C(n=10)$ & $7.054 \pm 0.017$ & $50.300 \pm 0.943$ & $48.100 \pm 5.975$ & $13.500 \pm 0.342$ & $-16.500 \pm 0.847$ & $-14.600 \pm 0.653$ & $12.000 \pm 0.422$ & $13.446 \pm 0.669$ & $0.882 \pm 0.013$ \\
\hline$D(n=10)$ & $7.069 \pm 0.011$ & $51.100 \pm 0.640$ & $42.200 \pm 2.603$ & $14.400 \pm 0.400$ & $-16.600 \pm 0.452$ & $-15.000 \pm 0.516$ & $12.800 \pm 0.416$ & $13.524 \pm 0.357$ & $0.869 \pm 0.010$ \\
\hline$E(n=10)$ & $7.050 \pm 0.009$ & $50.500 \pm 0.703$ & $45.300 \pm 5.931$ & $13.000 \pm 0.224$ & $-16.500 \pm 0.563$ & $-14.800 \pm 0.467$ & $12.100 \pm 0.233$ & $13.445 \pm 0.445$ & $0.891 \pm 0.012$ \\
\hline Average & $7.058 \pm 0.013$ & $50.900 \pm 0.757$ & $44.980 \pm 4.287$ & $13.800 \pm 0.363$ & $-16.480 \pm 0.623$ & $-14.760 \pm 0.562$ & $12.360 \pm 0.384$ & $13.430 \pm 0.492$ & $0.878 \pm 0.012$ \\
\hline
\end{tabular}

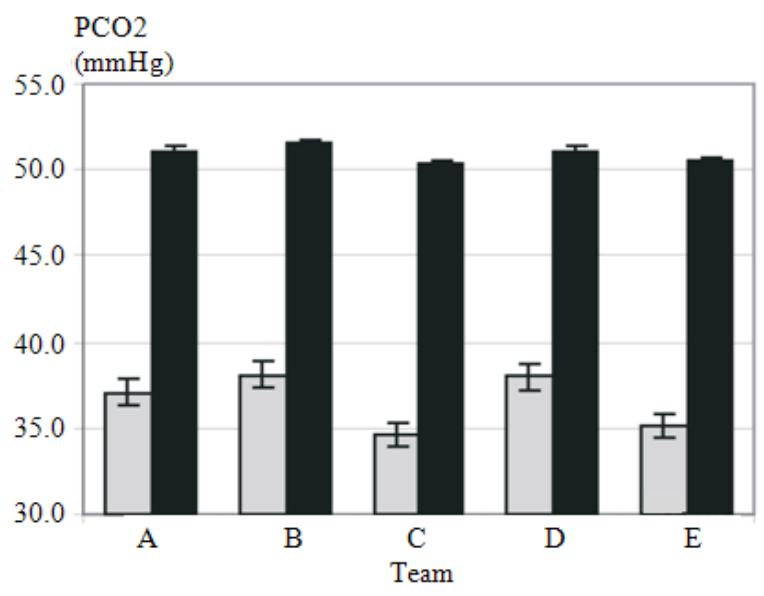

Fig. 2: The $\mathrm{Pco}_{2}$ values dynamics before and after the official game at male teams

$\mathrm{PO} 2$

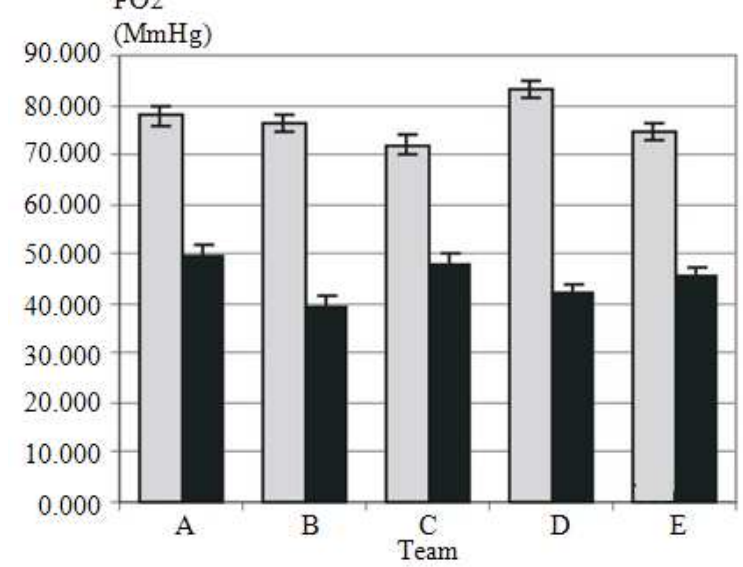

Fig. 3: The $\mathrm{Po}_{2}$ values dynamics before and after the official game at male teams

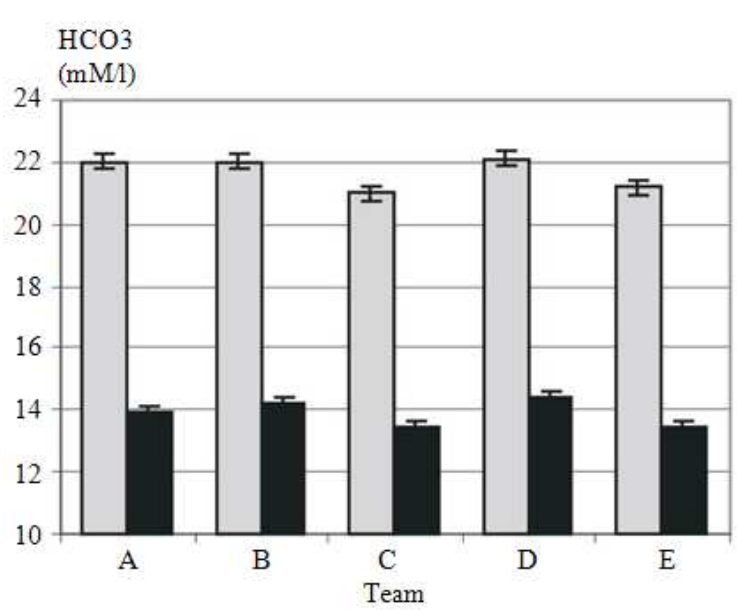

Fig. 4: The $\mathrm{HCO}_{3}$ values dynamics before and after the official game at male teams

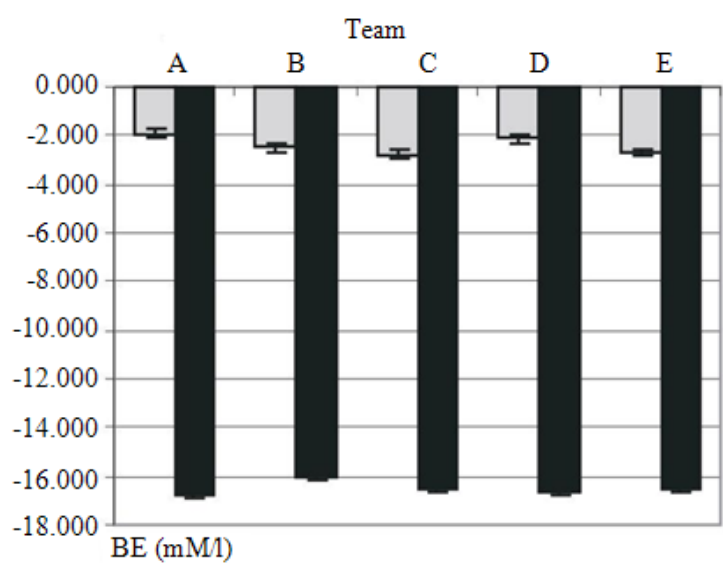

Fig. 5: The Bases Excess (BE) values dynamics before and after the official game at male teams 


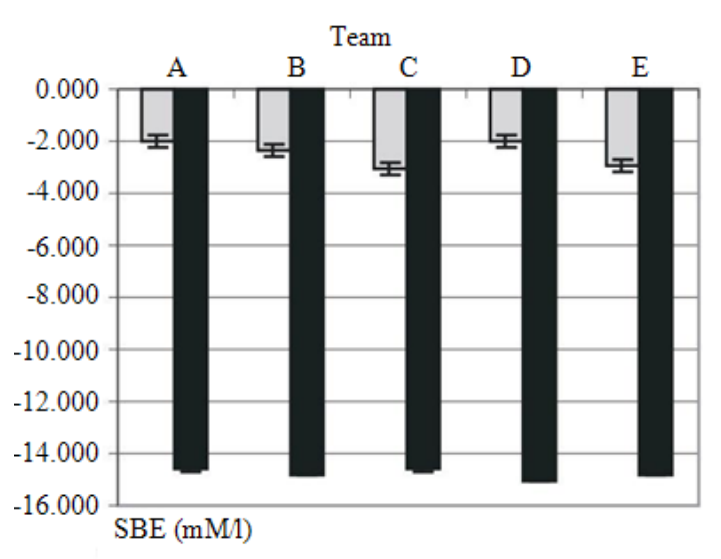

Fig. 6: The Standard Bases Excess (SBE) values dynamics before and after the official game at male teams

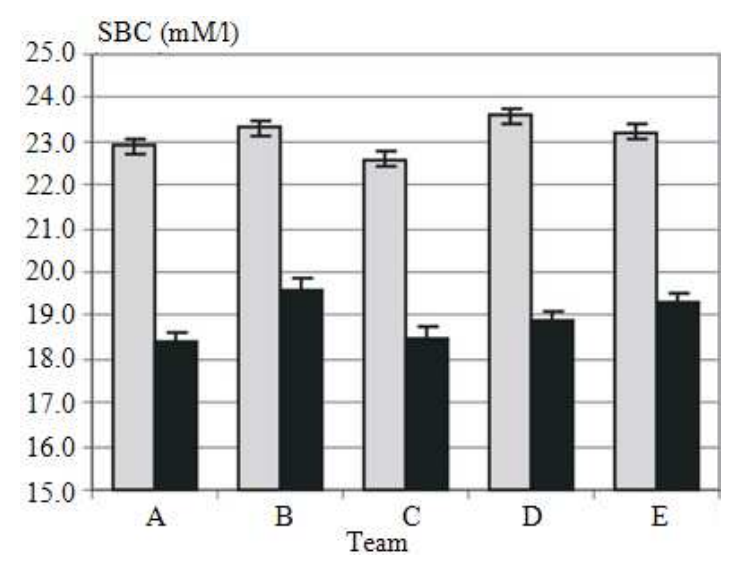

Fig. 7: The Standard Bicarbonate (SBC) values dynamics before and after the official game at male teams

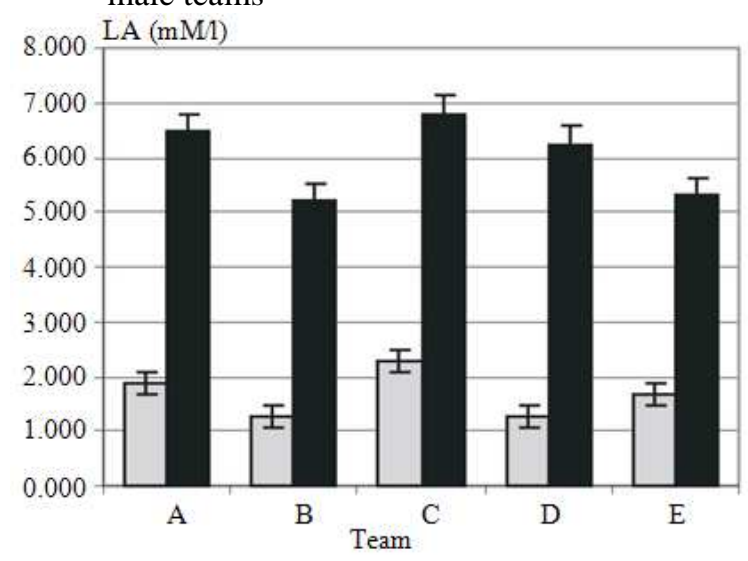

Fig. 8: The Lactic Acid (LA) values dynamics before and after the official game at male teams

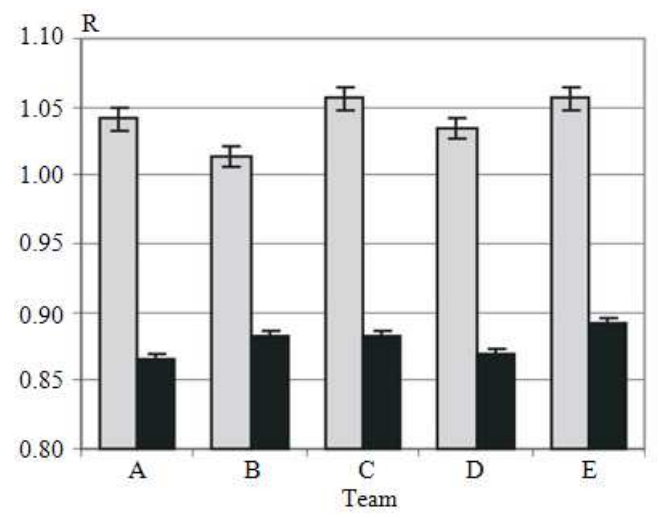

Fig. 9: The metabolic unbalance $(\mathrm{R})$ values dynamics before and after the official game at male teams

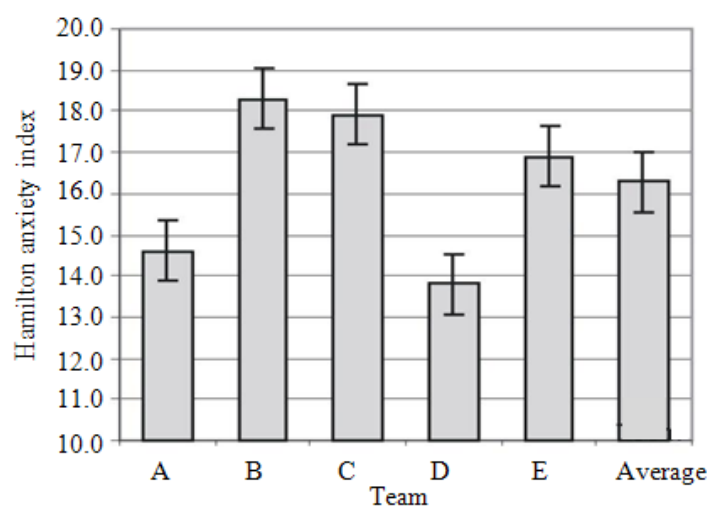

Fig. 10: The Hamilton anxiety index $(\mathrm{CH})$ values dynamics before the official game at male teams

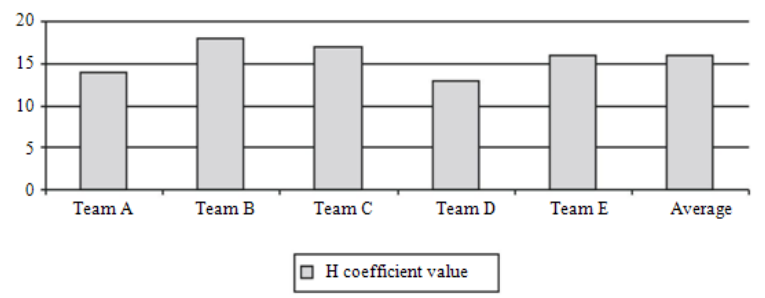

Fig. 11: The team average anxiety values dynamics, according to the Hamilton scale

Table 3: The average values of the Hamilton anxiety coefficient $(\mathrm{CH})$ at male teams level (the values represent the arithmetical mean \pm ES)

\begin{tabular}{ll}
\hline Team & Male \\
\hline $\mathrm{A}(\mathrm{n}=10)$ & $14.600 \pm 0.991$ \\
$\mathrm{~B}(\mathrm{n}=10)$ & $18.300 \pm 1.155$ \\
$\mathrm{C}(\mathrm{n}=10)$ & $17.900 \pm 1.080$ \\
$\mathrm{D}(\mathrm{n}=10)$ & $13.800 \pm 0.904$ \\
$\mathrm{E}(\mathrm{n}=10)$ & $16.900 \pm 1.464$ \\
Average & $16.300 \pm 1.119$ \\
\hline
\end{tabular}




\section{J. Social Sci., 7 (3): 309-314, 2011}

Under official competition conditions, the tested parameters values dynamics at male teams is the following (Fig. 1-10, Table 1-2):

- The $\mathrm{pH}$ drops significantly at all teams $(\mathrm{p}<0,001)$

- $\mathrm{Pco}_{2}$ is significantly increased at all teams $(\mathrm{p}<0,001)$

- $\mathrm{Po}_{2}$ drops very significantly at teams $\mathrm{B}$ and $\mathrm{D}$ $(\mathrm{p}<0,001)$ and significantly at teams $\mathrm{A}, \mathrm{C}$ and $\mathrm{E}$ $(\mathrm{p}<0,05)$

- $\mathrm{HCO}_{3}{ }^{-}$drops very significantly at all teams $(\mathrm{p}<0,001)$

- $\quad B E$ drops very significantly at all teams $(p<0,001)$

- $\quad$ SBE drops very significantly at all teams $(p<0,001)$

- $\quad$ SBC drops very significantly at all teams $(\mathrm{p}<0,001)$

- LA (Blood lactic acid concentration) is significantly increased at all teams $(\mathrm{p}<0,001)$

- $\mathrm{R}$ drops very significantly at all teams $(\mathrm{p}<0,001)$

The anxiety state before the official match: During rest, before every male team match, we have conducted the completion of Hamilton anxiety state testing forms. The results are presented in Table 3.

As we can see in Table 3, there is a state of high anxiety at three of the five teams, one team is situated at the limit between minor and high anxiety and one team is characterized by a state of minor anxiety, but the values are very close towards the high state.

$(\mathrm{CH}=14.6)$ (Fig. 11).

\section{DISCUSSION}

At the studied teams we have observed the following aspects: The excess carbon dioxide determines the increase of the $\mathrm{CO}_{2}$ partial pressure that is eliminated by lungs through hyperventilation, induced by the direct action of the $\mathrm{CO}_{2}$ dissolved in the spinal liquid on the bulbar respiratory centers-respiratory compensation. The metabolic acidosis is also determined by the significant decrease of the $\mathrm{HCO}_{3}{ }^{-}$values, from 21.08$13.8 \mathrm{~mm} \mathrm{~L}{ }^{-1}$. The value of the $\mathrm{HCO}_{3}{ }^{-} / \mathrm{CO}_{2}$ ratio is increased by reducing the numerator and increasing the denominator, which explains the extremely low values (close to the $\mathrm{pH}$ lower physiological limits) of 7.058. These extreme variations also indicate the fact that the respiratory compensation through pulmonary ventilation phenomena is insufficient. We can say that boys experience a state of decomposition, following the extreme effort during the game. It would have been interesting to see if in this decompensate state also intervenes a supplementary mechanism through which the lactic acid accumulation $\mathrm{H}+$ ions surplus, a surplus that overcomes the respiratory compensation capacity, are being eliminated renally. Usually, in the case of metabolic acidosis determined by maximal physical effort, the renal compensating mechanisms are intervening, but after a longer period of time, 1-2 days The decrease to extreme values of the Base Excess (BE) and the Standard Base Excess (SBE) indicates the use of these bases in the $\mathrm{H}^{+}$ions excess metabolization.

Very high LA values indicate an anaerobic intense energetic use, probably by stimulating the hormonal axis (hypothalamus-pituitary gland-medullo adrenal gland), by increasing the corticoliberin secretion and by stimulating the sympathetic vegetative nervous system.

The blood buffering capacity is strongly affected during play through the decrease of base excess at very low physiological levels, the quantity of bases required to re-establish the acid-base balance being extremely high (BE has values below-15 mm L $\mathrm{m}^{-1}$ ). The values of $\mathrm{pH}(7.058 \pm 0.013)$, of $\mathrm{HCO}_{3}^{-}\left(13.8 \pm 0.363 \mathrm{~mm} \mathrm{~L}^{-1}\right)$ and of LA $\left(12.36 \pm 0.38 \mathrm{~mm} \mathrm{~L}^{-1}\right)$ indicate an extremely high charge during play, equivalent with a mechanical work of over $500 \mathrm{~W}$. These values situate the competitive handball among the sports that are characterized by an extreme physical effort. This is also confirmed by the very significant variations of the $R$ metabolic unbalance coefficient, which drops to 0.878 values outside the normal physiological limits. These values registered during the official games are also due to the high computational stress tolerated by the players given the stakes of the competition, a state that is reflected in anxiety index values of 16.300 .

\section{CONCLUSION}

The results obtained from our research confirm the fact that the physiological modifications during competition stress conditions at competitive handball players can be studied, monitored and influenced in a positive manner in order to obtain superior sportive performances on a national and international level. The purpose of this study being accomplished, we can say that the research captured also the existence of other stress factors that act upon the handball players, also through the modification of tested physiological parameters. These other factors add to the ones that characterize the physical effort. They are:

- The attitude of the audience

- The attitude of the coach during the whole time of the game and especially during breaks

- The environmental playing conditions (indoor temperature, light intensity, field condition, the location of the field in relation to the stand and the side bench) 
- The relationships between players

- The traumatic experience related to the competition

- The opponent's value

- Refereeing manner

- The importance of the match (competition)

- Although the intensity of the handball specific motive actions is very close to the one during training, in the studied group, the tested parameters values were influenced differently. If we count the Hamilton anxiety coefficient value $(\mathrm{CH})$, we find that the disturbance degree of the acid-base balance $(\mathrm{R}=0.878 \pm 0.012)$ present at the tested athletes is in direct correlation with this coefficient

- The charge of the performances in relation to the tested parameters values is comparable to the one of the oarsmen (over 1000W) during certain prolonged attacks and during most of the defense actions. The modifications of the tested physiological parameters determine changes of their values, much more accentuated than the ones encountered at tennis players, football players or volleyball players. Close physiological parameters values ( $\mathrm{pH}, \mathrm{LA})$ were encountered at rugby players, basketball players and, even greater, at hockey players, during the first $15 \mathrm{~min}$ of the game

- The values obtained at handball players cannot be compared with the ones obtained in tennis, gymnastics, some athletics and swimming events, due to the different specific kind of effort, the lack of direct physical contact with the opponent, as well as the lack of certain specific stress factors (the public, the side bench, coach intervention, referee intervention) and the presence of other stress factors in certain sports (water and room temperature, wind speed, interaction with different apparatus specific to the events)

Thus, following the results we can say that the purpose of this study was accomplished, confirming some of the theories in the sportive literature from a psychological point of view of approaching the sportive competitions and the data that we have obtained can represent a starting point in the thorough study of the handball coaching principles.

\section{REFERENCES}

Acsinte, A. and E. Alexandru, 2004. Biochemical and physiological changes in handball players during a specific high intensity training program. Scientific Publicationl.

http://www.pubs.ub.ro/?pg=revues\&rev=scsb\&nu $\mathrm{m}=200611$ \& vol $=11$ \&aid $=2533$

Adamu, L., N.M. Adzahan, R. Abdullah and B. Ahmad, 2010. Effects of race distance on physical, hematological and biochemical parameters of endurance

horses. Am. J. Anim. Vet. Sci., 5: 244-248. DOI: 10.3844/ajavsp.2010.244.248

Alexandru, A. and A. Eftene, 2007. Physical Condition in High Performance Team Handball (requirements). University of Bacău. http://www.robinashs.eq.edu.au/home/abran28/Yea r\%2011/Unit\%202/Physical_condition_in_high_pe rformance_team_handball.pdf

Avraham, B., M. Gelkopf and Z. Solomon, 2003. Exposure to terrorism, stress-related mental health symptoms, and coping behaviors among a nationally, Representative Sample in Israel. JAMA., 290 : 612-620. DOI: 10.1001/jama.290.5.612

Baker, J., E. Brown, G. Hill, G. Phillips and R. Williams et al., 2002. Handgrip contribution to lactate production and leg power during high-intensity exercise. Med. Sci. Sports Exerc., 34: 1037-1040. DOI: 10.1097/00005768-200206000-00021

Hnidawei, M.A., M. MjallI and Z. Zayed, 2010. The Upper limit of physiological cardiac hypertrophy in elite male athletes. Am. J. Applied Sci., 7: 1327-1333. DOI: 10.3844/ajassp.2010.1327.1333

Kordi, M.R., M.H. Alizadeh and K. Letafatkar, 2009. The effect of exhausting exercise induced fatigue on the double-leg balance ofelite male athletes. J. Soc. Sci., 5: 445-451. DOI: 10.3844/jssp.2009.445.451 http://www.doaj.org/doaj?func=abstract $\&$ id=483345 